\title{
A 3-33 GHz PHEMT MMIC Distributed Drain Mixer
}

\author{
Kuo-Liang Deng, Huei Wang, Senior Member, IEEE \\ Dept. of Electrical Engineering and Graduate Institute of Communication Engineering, \\ National Taiwan University, Taipei, Taiwan, 10617, ROC
}

\begin{abstract}
A compact wide-band GaAs PHEMT MMIC distributed drain mixer covering the RF frequency from 3 to $33 \mathrm{GHz}$ is reported in this paper. The measured results show that the conversion loss of the distributed drain mixer is better than $4 \mathrm{~dB}$ over the frequency range at $\mathrm{LO}$ power $13 \mathrm{dBm}$ without IF amplification. Using the matching circuit in the output of the FETs, the LO-to-IF and LO-to-RF isolations are better than $19 \mathrm{~dB}$ from 3 to $33 \mathrm{GHz}$. This mixer utilized a simple distributed topology with single-gate HEMTs and achieved a very broad band performance comparable to the cascode or dual-gate distributed mixers. The overall chip size of this MMIC is only $1.7 \times 1 \mathrm{~mm}^{2}$.
\end{abstract}

\section{INTRODUCTION}

The distributed mixer is a promising technique to realize MMIC mixers with ultra-wideband performance. Similar to the distributed amplifiers [1]-[3], the distributed topology can be used to design MMIC mixers with decade bandwidths that are insensitive to MMIC process variations.

The distributed mixers can be implemented using either single FETs [5]-[7], [13], or dual-gate or cascode FETs [4], [8]-[12]. The use of dual-gate or cascode FETs as the mixing devices in distributed mixer circuits provides inherently good isolation between $\mathrm{LO}$ and $\mathrm{RF}$ signals when they are applied to the separate gates. However, one may need special FET device layout and models in the dual gate or cascode FET mixer designs.

In this paper, a compact, simple MMIC distributed drain mixer using single-gate HEMT devices is presented. The measurement results show that the conversion loss of the mixer is better than $4 \mathrm{~dB}$ from the RF frequency 3 to 33 $\mathrm{GHz}$ at $\mathrm{LO}$ power $13 \mathrm{dBm}$ without IF amplification. Using the matching circuit in the output of the FETs, the measured LO to IF and LO to RF isolations are better than $19 \mathrm{~dB}$ from 3 to $33 \mathrm{GHz}$. Without using dual-gate or cascode FETs, this MMIC mixer still achieves a broadband and high isolation performance, which rivals the previously published results [4]-[13].

\section{DEVICE CHRACTERISTICS AND MMIC FABRICATION}

The MMIC mixers were fabricated using GaAs-based pseudormorphic HEMT (PHEMT) MMIC foundry process provided by TRW [14]. The device is a $0.15-\mu \mathrm{m}$ gatelength PHEMT with a unit current gain frequency $\left(f_{T}\right)$ of $81 \mathrm{GHz}$. The passive components include GaAs thin film resistor, MIM capacitor, and via hole through $100-\mu \mathrm{m}$ GaAs substrate. The entire chip is also protected by silicon-nitride passivation for reliability concern.

\section{CIRCUIT DESIGN}

The circuit schematic diagram of the four-section distributed drain mixer is shown in Fig. 1. There are four $0.15-\mu \mathrm{m}$ PHEMTs with a gate periphery of $200 \mu \mathrm{m}$. The PHEMTs are biased near the knee region, where the nonlinear characteristics of drain-to-source current versus drain-to-source voltage are used for frequency mixing. Microstrip lines are used to form the artificial gate and drain transmission lines, and for phase equalization of the signal on the drain transmission line. A matching circuit is designed in the output of the PHEMTs to maximize the IF output power and offer the LO-to-IF isolation. The mixer performance is simulated via the harmonic balance technique implemented in the commercial CAD software (LIBRA $^{\mathrm{TM}}$ from HP-EESOF). The nonlinear HEMT model used in the simulation is Curtice cubic model provided by the foundry. Fig. 2 shows the photo of the MMIC chip, with die size of $1.7 \times 1 \mathrm{~mm}^{2}$.

\section{CIRCUIT PERFORMANCE}

The mixer was measured via on wafer probing. The PHEMTs are biased near the knee region of the DC-IV curve, with $\mathrm{V}_{D S}=1.1 \mathrm{~V}$ and $\mathrm{V}_{\mathrm{GS}}=-0.7 \mathrm{~V}$. The conversion loss and LO-to-IF, LO-to-RF isolations were evaluated for the mixer. The measured conversion loss results versus local oscillator power level from 2 to $18.5 \mathrm{dBm}$ at frequencies at $5,15,25 \mathrm{GHz}$ with IF is fixed at $1 \mathrm{GHz}$ and $\mathrm{RF}$ is at $6,16,26 \mathrm{GHz}$ are plotted in Fig. 3. It is observed that for LO drive level above $13 \mathrm{dBm}$, the conversion performance becomes saturated. The simulated and measured conversion loss versus LO frequencies from 2 to 
$32 \mathrm{GHz}$ with $\mathrm{RF}$ input power of $-10 \mathrm{dBm}$ and $\mathrm{LO}$ drive of $13 \mathrm{dBm}$ with $\mathrm{V}_{\mathrm{DS}}=1.1 \mathrm{~V}, \mathrm{~V}_{\mathrm{G} \mathrm{s}}=$ $-0.7 \mathrm{~V}$ and Ids $=70 \mathrm{~mA}$ were plotted in Fig. 4. The measured conversion loss is between 1 and $4 \mathrm{~dB}$ across the band and demonstrated a broadband performance. The simulation and measurement results agree to each other reasonably. The measured isolations versus LO frequency were illustrated in Fig. 5. The LO-to-RF and LO-to-IF isolations are greater than $19 \mathrm{~dB}$ covering the $\mathrm{RF}$ frequencies from 3 to $33 \mathrm{GHz}$. The simulation and measurement broad bandwidth RF and LO input matched characteristics of the distributed circuit topology are shown in Figure 6. Both ports have better than 5-dB return loss over most of the 5 to $31 \mathrm{GHz}$ bandwidth.

Fig. 7-9 show the RF input power at 6,16 and $26 \mathrm{GHz}$ versus IF output and the third order intermodulation products for LO power level of $13 \mathrm{dBm}$ at 5,15 and 25 $\mathrm{GHz}$, respectively. The measured two-tone input thirdorder intercept points are 10,12 , and $12 \mathrm{dBm}$. Table I summarized the features and performances of the previously published distributed mixers and this work. Compared with the previously published results [4]-[13], this MMIC mixer demonstrated the widest RF bandwidth performance. It is noted that the measured results in [6] only showed $\mathrm{LO}$ frequency to $25 \mathrm{GHz}$.

\section{CONCLUSION}

A compact and wide-band drain mixer using a simple single-gate HEMTs distributed topology is described in this paper. Using the matching circuit in the output of the HEMTs, the conversion loss is less than $4 \mathrm{~dB}$ and the LOto-RF and LO-to-IF isolations are better than $19 \mathrm{~dB}$ at RF frequency from 3 to $33 \mathrm{GHz}$, which are comparable to those of the cascode or dual-gate distributed mixers. It demonstrated the widest RF bandwidth compared with the previously published distributed mixers.

\section{ACKNOWLEDGEMENT}

This work is supported in part by National Science Council of Taiwan, ROC (NSC 89-2213-E-002-178 and NSC 89-2219-E-002-042) and the Research Excellence Program funded by Ministry of Education, ROC (ME 89E-FA06-2-4). The MMIC foundry service is provided by TRW through the Chip Implementation Center (CIC) of Taiwan. The authors would like to thank Dr. Ying-Zung Juang of $\mathrm{CIC}$ for the foundry service coordinate effort.

\section{REFERENCES}

[1] Y. Ayasli, R. L. Mozzi, J. L. Vorhaus, L. D. Reynolds, R. A. Pucel, "A monolithic GaAs 1-13 GHz traveling-wave amplifier," IEEE Trans. on Microwave Theory and Tech., vol. 30, no. 7, pp. 976-981, July, 1982.

[2] J. B. Beyer and S. N. Prasad, "MESFET distributed amplifier design guidelines," IEEE Trans. on Microwave Theory and Tech., vol. 32, no. 3, pp. 268-275, March, 1984.

[3] B. Agarwal, A. E. Schmitz, J. J. Brown, M. Matloubian, M. G. Case, M. Le, M. Lui, Mark J. W. Rodwell, "112-GHz, 157-GHz, and 180-GHz InP HEMT Traveling-wave amplifier," IEEE Trans. on Microwave Theory and Tech., vol. 46, no. 12, pp. 2553-2559, Dec., 1998.

[4] M. Lacon, K. Nakano, G. S. Dow, "A wide band distributed dual gate HEMT mixer," 1988 GaAs IC Symposium Digest, pp. 173-176.

[5] On San A. Tang and C. Aitchison, "A very wide-band microwave MESFET mixer using the distributed mixer principle," IEEE Trans. on Microwave Theory and Tech., vol. 33, no. 12, pp. 1470-1478, Dec., 1985.

[6] D. Hollmann, R. Heilig, G. Baumann, "A monolithic broadband $10-50 \mathrm{GHz}$ distributed HEMT mixer including active LO-RF combiner," 1994 GaAs IC Symposium Digest, pp. 100-103.

[7] A. H. Darsinooieh, O. Palamutcuoglu, "On the theory and design of subharmonically drain pumped microwave MESFET distributed mixer," 1996 International IEEE MTT-S Symposium Digest, vol. 2, pp. 595-598, June, 1996.

[8] W. Titus, M. Miller, "2-26 GHz MMIC frequency converter," 1988 GaAs IC Symposium Digest, pp. 181-184.

[9] T. S. Howard, A. M. Paivo, "A distributed $1-12 \mathrm{GHz}$ dualgate FET mixer," 1986 International IEEE MTT-S Symposium Digest, vol. 2, pp. 329-332, June, 1986.

[10] K. S. Ang, I. D. Robertson, "Multiple-FET mixer analysis with applications to the cascode distributed mixer," 1999 High Frequency Postgraduate Student Colloquium, pp. $22-$ 27, June, 1999.

[11] I. D. Robertson, A. H. Aghvami, "A novel 1 to $14 \mathrm{GHz}$ monolithic matrix distributed FET mixer," Proceeding of the $21^{\text {st }}$ European microwave conference, Sept. pp. 489-494, 1991.

[12] W. Titus, Y. Tajima, R. A. Pucel, A. Morris, "Distributed monolithic image rejection mixer," 1986 GaAs IC Symposium Digest, pp. 191-194.

[13] R. Majidi-Ahy, C. Nishimoto, J. Russell, W. Ou, S. Bandy, G. Zdasiuk, "23-40 GHz InP HEMT MMIC distributed mixer," 1992 International IEEE MTT-S Symposium Digest, vol. 2, pp. 1063-1066, June, 1992.

[14] TRW 0.15 PHEMT V4.O Design Manual, TRW Inc., 1998 
Table I

Summary of the previously published distributed mixers and this work

\begin{tabular}{|c|c|c|c|c|c|c|c|c|c|c|c|}
\hline \multirow[t]{2}{*}{ Ref. } & \multicolumn{3}{|c|}{ Frequency (GHz) } & \multicolumn{5}{|c|}{ Performance } & \multirow{2}{*}{$\begin{array}{c}\mathbf{P}_{\mathrm{LO}} \\
(\mathrm{dBm})\end{array}$} & \multicolumn{2}{|l|}{ Design features } \\
\hline & $\mathrm{RF}$ & LO & IF & $\begin{array}{l}\text { Conversion } \\
\text { Gain }(\mathrm{dB})\end{array}$ & $\begin{array}{l}\text { LO-RF } \\
\text { Isolation } \\
\text { (dB) }\end{array}$ & $\begin{array}{l}\text { LO-IF } \\
\text { Isolation } \\
\text { (dB) }\end{array}$ & $\begin{array}{c}\mathrm{P}_{1 \mathrm{~dB}} \\
\text { (Input) } \\
(\mathrm{dBm})\end{array}$ & $\begin{array}{c}\text { IP3 } \\
\text { (Input) } \\
\text { (dBm) }\end{array}$ & & Process & $\begin{array}{l}\text { Number } \\
\text { of } \\
\text { sections }\end{array}$ \\
\hline [4] & $5-17$ & $6-18$ & 1 & $-1 \sim-6$ & & & & & 17 & GaAs $0.25 \mu \mathrm{m}$ HEMT MMIC & 4 \\
\hline [5] & $2-10$ & & 0.01 & 1 & & & & & 9 & Hybrid (alumina) & 2 \\
\hline [6] & & $10-50$ & 4.6 & $0 \sim-4$ & & & & & 5 & GaAs $0.2 \mu \mathrm{m}$ HEMT MMIC & 4 \\
\hline [7] & $2-14$ & & 0.07 & $0 \sim-1$ & & 20 & & & 16 & Hybrid (Duroide) & 3 \\
\hline [8] & $2-26$ & & 0.5 & $5-11$ & 20 & & 5 & $11-15$ & 12 & $\begin{array}{l}\text { GaAs } 0.7 \mu \mathrm{mHEMT} \text { MMIC } \\
\text { Contain filter and amplifier }\end{array}$ & 4 \\
\hline [9] & $1-12$ & & 0.4 & $0 \sim-3$ & & & 8 & & 11 & $\begin{array}{l}\text { Hybrid (0.38-mm thick alumina) } \\
\text { GaAs } 0.5 \mu \text { m dual-gate HEMT }\end{array}$ & 4 \\
\hline [10] & $2-20$ & & 1 & $2-4$ & & & & & 10 & GaAs PHEMT MMIC & 4 \\
\hline [11] & $3-15$ & & 0.5 & $3 \sim 0$ & 20 & & & & 12.5 & GaAs PHEMT MMIC & 2 \\
\hline [12] & $14-20$ & 12 & $2-8$ & -6 & 30 & 20 & & & 12.6 & GaAs $0.7 \mu$ m dual-gate FET MMIC & 4 \\
\hline This work & $3-33$ & $2-32$ & 1 & $-1 \sim-4$ & 20 & 19 & 0 & $10-12$ & 13 & GaAs $0.15 \mu \mathrm{m}$ PHEMT MMIC & 4 \\
\hline
\end{tabular}

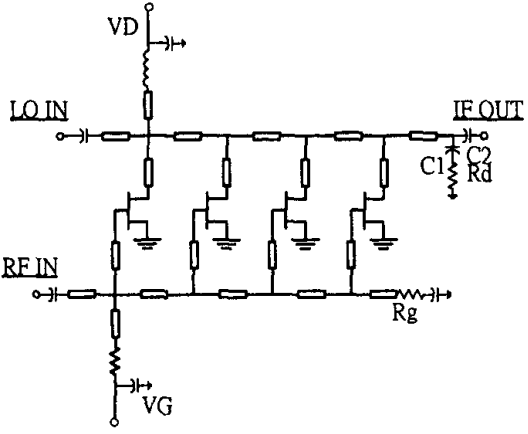

Fig. 1. The circuit schematic diagram of the MMIC distributed drain mixer.

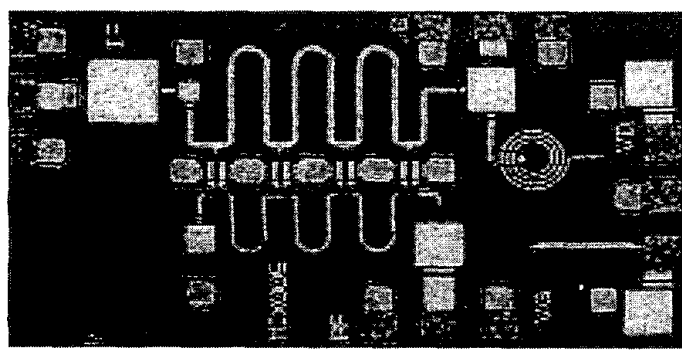

Fig. 2. The chip photo of the MMIC distributed drain mixer with chip size of $1.7 \times 1 \mathrm{~mm}^{2}$.

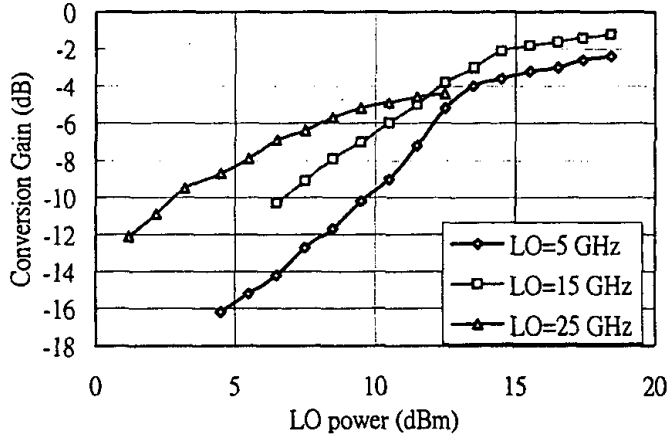

Fig. 3. Measured mixer conversion gain as a function of applied LO power with IF fixed at $1 \mathrm{GHz}$ for LO frequencies at 5,15 and $25 \mathrm{GHz}$ with $\mathrm{V}_{\mathrm{DS}}=1.1 \mathrm{~V}, \mathrm{~V}_{\mathrm{GS}}=$ $-0.7 \mathrm{~V}$.

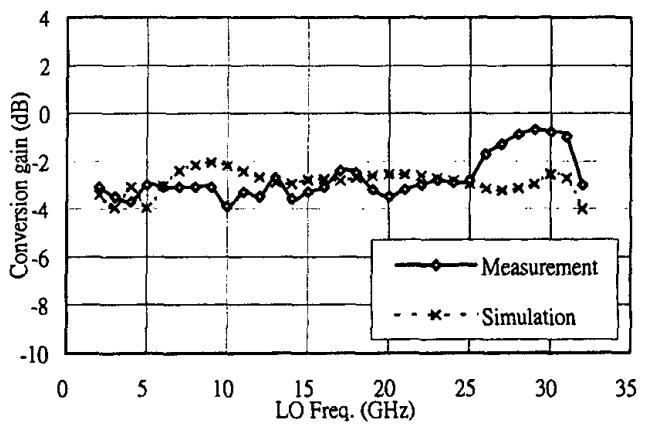

Fig. 4. Simulated and measured conversion gain versus LO frequency of the MMIC distributed drain mixer. IF frequency is fixed at $1 \mathrm{GHz}$ and $\mathrm{RF}$ and $\mathrm{LO}$ input power level are -10 and $13 \mathrm{dBm}$ for frequency down conversion with $V_{D S}=1.1 \mathrm{~V}, V_{G S}=-0.7 \mathrm{~V}$ 


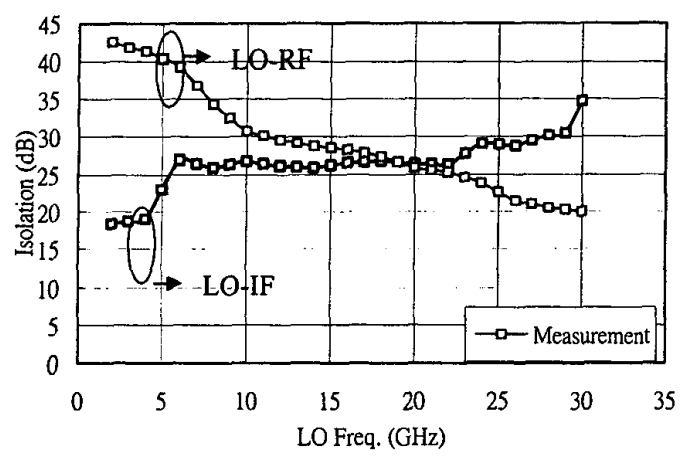

Fig. 5. Measured isolation versus LO frequency of the MMIC distributed drain mixer. LO input power level is $13 \mathrm{dBm}$ with $\mathrm{V}_{\mathrm{DS}}=1.1 \mathrm{~V}, \mathrm{~V}_{\mathrm{GS}}=-0.7 \mathrm{~V}$.

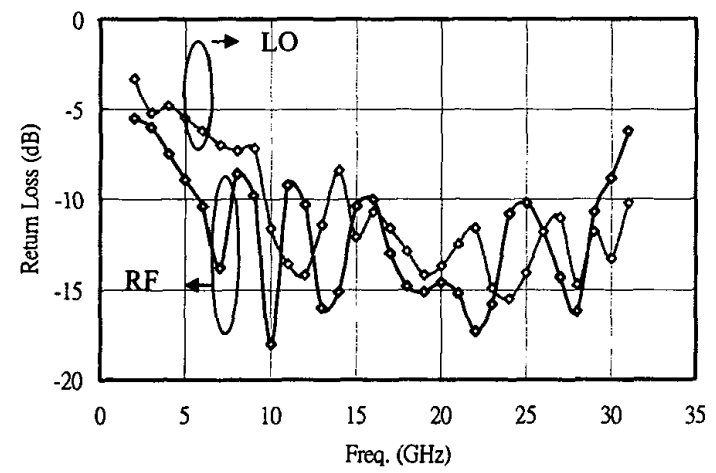

Fig. 6. Simulated and measured LO and RF return loss versus frequency of the MMIC distributed drain mixer. $L O$ and $R F$ input power level is 13 and $-10 \mathrm{dBm}$.

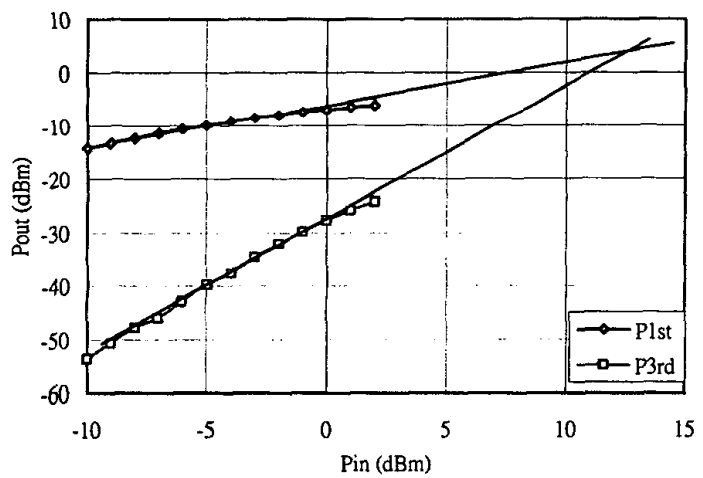

Fig. 7. Measured IF output and the third order intermodulation products versus RF input power of the MMIC distributed drain mixer. LO input power level and frequency are $13 \mathrm{dBm}$ and $5 \mathrm{GHz} . \mathrm{f}_{\mathrm{RF} 1}=6.1 \mathrm{GHz}, \mathrm{f}_{\mathrm{RF} 2}=$ $6 \mathrm{GHz}, \mathrm{V}_{\mathrm{DS}}=1.1 \mathrm{~V}, \mathrm{~V}_{\mathrm{GS}}=-0.7 \mathrm{~V}$.

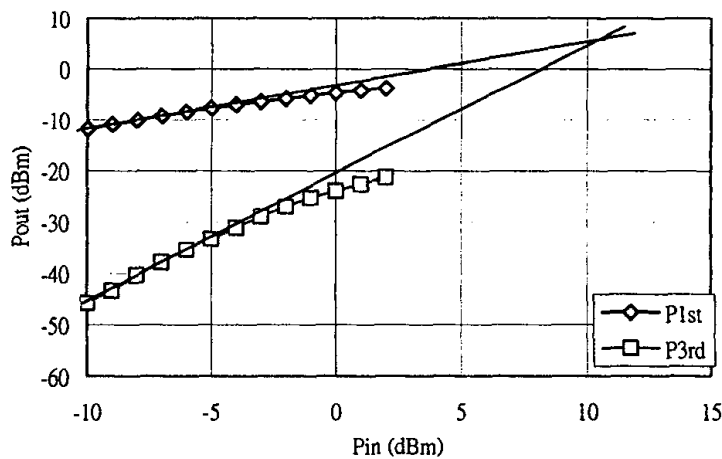

Fig. 8. Measure IF output and the third order intermodulation products versus $R F$ input power of the MMIC distributed drain mixer. LO input power level and frequency are $13 \mathrm{dBm}$ and $15 \mathrm{GHz} . \mathrm{f}_{\mathrm{RF} 1}=16.1 \mathrm{GHz}, \mathrm{f}_{\mathrm{RF} 2}$ $=16 \mathrm{GHz}, \mathrm{V}_{\mathrm{DS}}=1.1 \mathrm{~V}, \mathrm{~V}_{\mathrm{GS}}=-0.7 \mathrm{~V}$.

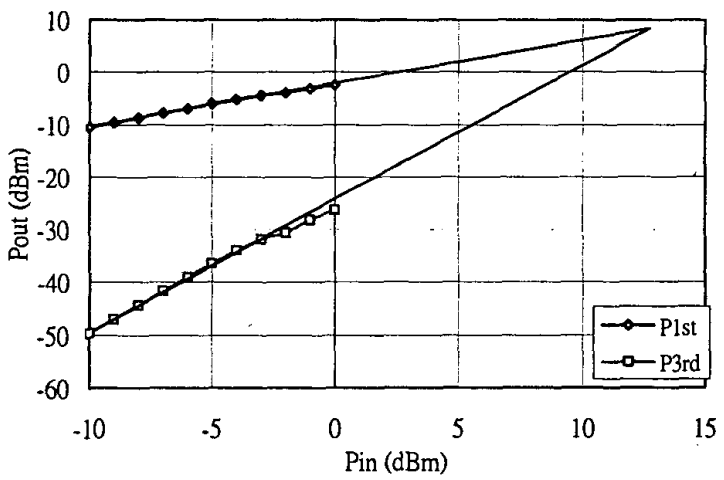

Fig. 9. Measured IF output and the third order intermodulation products versus $R F$ input power of the MMIC distributed drain mixer. LO input power level and frequency are $13 \mathrm{dBm}$ and $25 \mathrm{GHz}$. $\mathrm{f}_{\mathrm{RF} 1}=26.1 \mathrm{GHz}, \mathrm{f}_{\mathrm{RF} 2}$ $=26 \mathrm{GHz}, \mathrm{V}_{\mathrm{DS}}=1.1 \mathrm{~V}, \mathrm{~V}_{\mathrm{GS}}=-0.7 \mathrm{~V}$. 